\title{
Barriers and solutions: raising public awareness of fish migration in the rivers around the North Sea-a Living North Sea (LNS) project special issue
}

\author{
David R. Green
}

Published online: 22 January 2014

(C) Springer Science+Business Media Dordrecht 2014

\section{The Living North Sea project}

Today there is considerable published research about fish habitat and fish migration in the scientific literature, but how many of us who see and use our streams and rivers every day for recreational purposes such as fishing and canoeing really know very much about the fish that live in our streams and rivers and the lifecycle of these different fish species on their migratory routes from sea to source?

In 2009, an Interreg IVB-funded North Sea Region project with 15 European partners set about tackling this lack of knowledge and understanding through a project called the Living North Sea (LNS). The Living North Sea (LNS) project (www.living-north-sea.eu) sought to identify key issues concerning fish migration, barriers and the different solutions that could be used to reconnect the rivers and deltas around the North Sea Region (Fig. 1).

The project addressed knowledge gaps about the fish populations that depend on free movement between the North Sea and freshwater systems; considered innovative fish migration measures; collaborated with local water management authorities and policy makers; and created greater public awareness about the North Sea. Three essential aspects concerning the management of migratory fish were also important to this project: the fish migration routes; threats such as man-made barriers; how to influence future environmental policy at a regional, national and international level; and finding new ways to inform, educate and engage the general public.

D. R. Green $(\bowtie)$

AICSM - University of Aberdeen, Scotland, UK

e-mail: d.r.green@abdn.ac.uk

\section{Barriers to fish migration}

In the North Sea Region deltas and estuaries are often inaccessible to migratory fish species and many more have barriers (Fig. 2) along the river length-such as dams and sluices-which prevent access to spawning grounds. Whilst some attempts to accommodate the fish migration have been made such as fish lifts and fish ladders, these have not always been entirely successful.

Today, there is growing support for the removal of barriers to migration where possible. To this end the LNS partnership focused on raising awareness about better and more innovative migration measures, such as passages or sluice management to help reduce such barriers and even the loss of fish en route. In addition, a number of local demonstration projectswhere many fish species like the eel, salmon, lamprey, and sea trout are prevented from reaching their spawning and breeding grounds - were highlighted as examples where better solutions are possible Although work on migratory routes focused on sea trout, eel, and salmon in particular, the findings are also be applicable to many other species.

\section{Communicating information}

Disseminating and communicating the findings of this project to policy-makers, local decision-makers, scientists, and the public were also an important outcome. Healthy fisheries are critical to sustainable development and the good ecological status of the rivers upon which we depend. The project therefore placed emphasis on promotion and publicity because the effect of barriers on fish populations is often not considered when dealing with other environmental issues such as flooding, drainage, or renewable power generation.

One important communication outlet for the project was an invitation from the JCCPM to all partners of the 


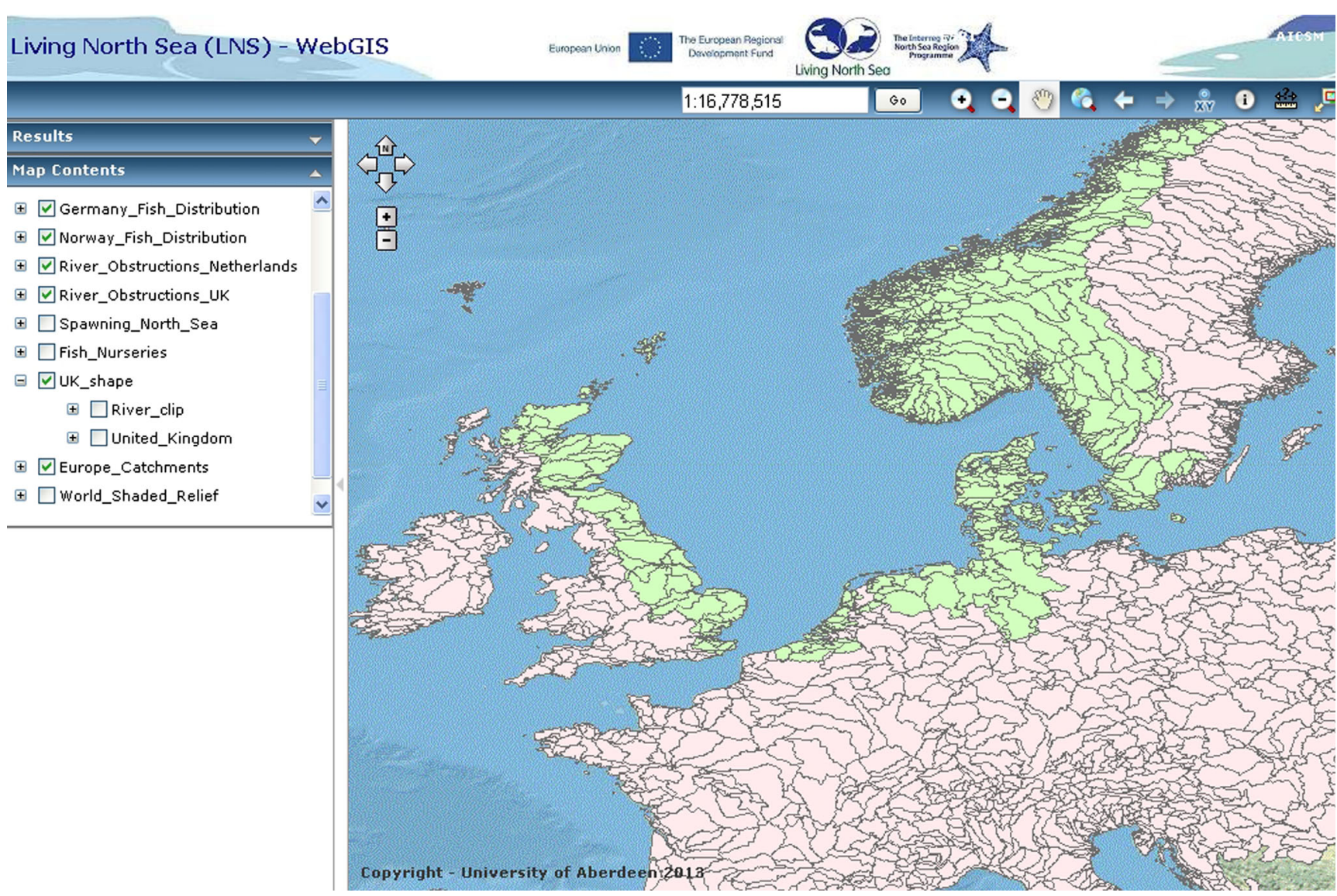

Fig. 1 The North Sea Region (Source: The Living North Sea (LNS) WebGIS - http://www.living-north-sea.eu/webgis/)

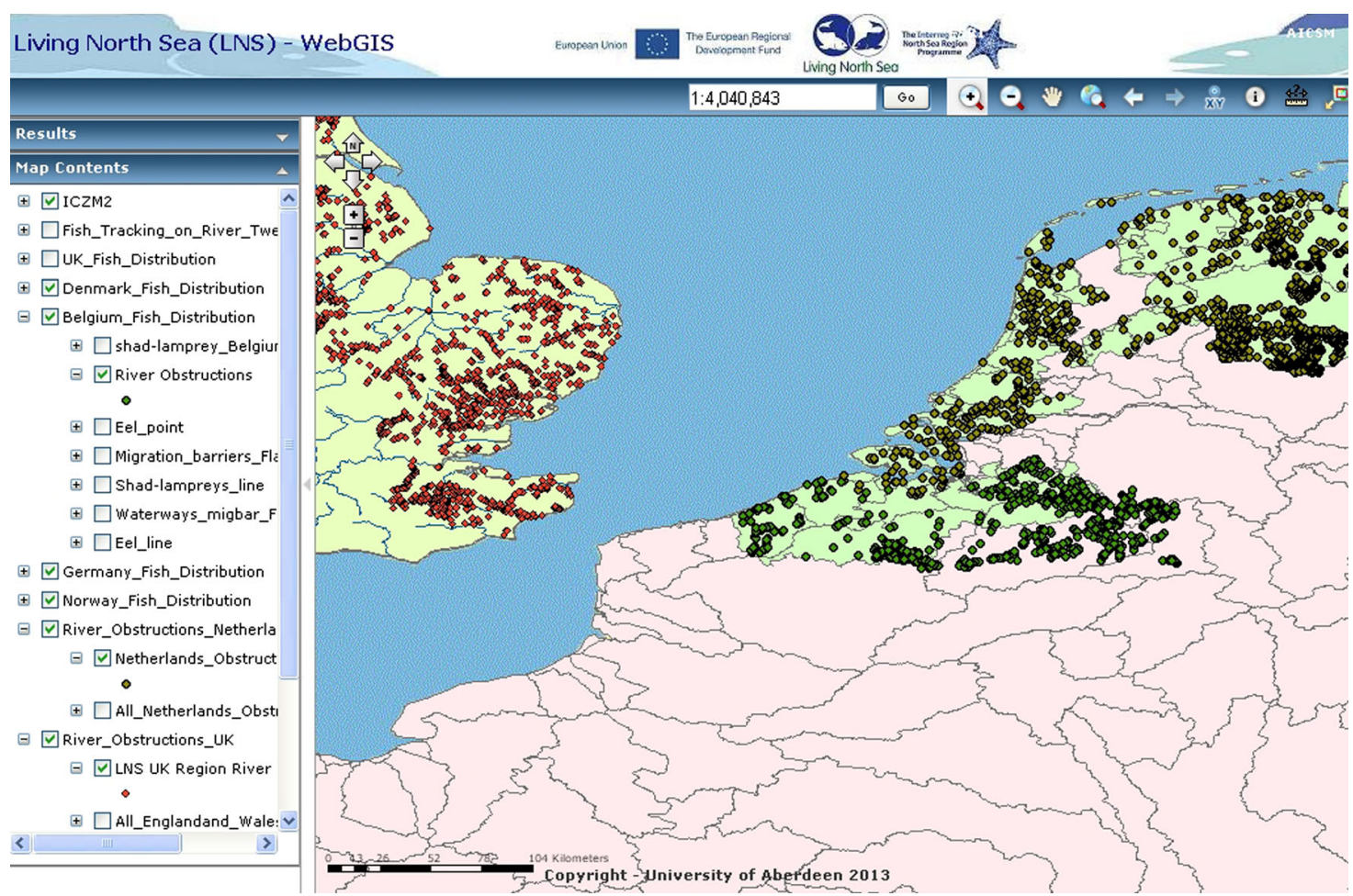

Fig. 2 Barriers to fish migration in Belgium, The Netherlands and the UK (Source: The Living North Sea (LNS) WebGIS—http://www.living-northsea.eu/webgis/) 
Living North Sea Project to submit scientific papers on various aspects of fish migration based upon the work of the Living North Sea Project for a Special LNS Project Issue.

The Special Issue comprises six papers from partners around the project study area including Belgium, Denmark, Germany, and The Netherlands that consider some of the important fish species such as the European Eel, the Glass Eel, Brown Trout, Salmon, and the Sturgeon. These papers discuss some of the issues concerning fish migration from the sea to the rivers (source), including: dispersal (Jonsson and Jonsson) the impact of barriers (Bangsgaard et al.; Breve et al. (1); Breve et al. (2) Mouton et al.), disease (Wysujack et al.), management (Breve et al. (2); Mouton et al.), and survival (Breve et al. (1)).

\section{Summary and conclusion}

The plight of fish in our rivers in a very important one that needs greater public awareness and education. Through the work of the LNS Project the experience and the expertise of fish migration specialists from around the North Sea Region will help to provide the link between science and policy-makers as well as to provide educational tools and resources that will help to improve our knowledge and understanding in the future. 